\section{John A. Brown, Jr. 1930-1987}

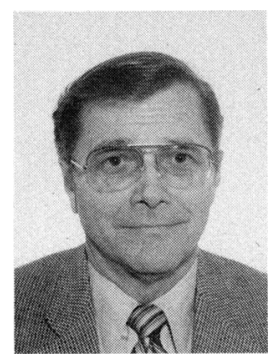

John A. Brown, Jr., died on 16 July at the age of 56 , following heart surgery. He had recently stepped down from a productive 17 year tour of service as chief of the Development Division at the National Meteorological Center (NMC). During this period his guidance was instrumental in achieving many pioneering steps in operational numerical weather prediction at NMC. The famous "LFM," or Limited-area Fine-mesh Model, was inaugurated in 1972. Global analyses (with the Hough function system devised by T. Flattery) were begun in 1974, together with a grid-point forecast model of global extent. In the mid-1970s, Brown recognized the importance of the forthcoming Global Weather Experiment, and this led him to emphasize the continued improvement of the global systems by his division. Because of this, the NMC was able to implement a global optimum-interpolation system as early as 1978, and a global spectral-forecast model in 1980. All of these advances represented first-time operational applications of their kind anywhere in the world. The availability of faster computers enabled him to support the implementation of the Nested Grid Model in 1985 as a replacement for the LFM. In his last years as division chief he played a major role in setting up the University Corporation for Atmospheric Research Visitors Program at the NMC and in bringing about increased cooperation with scientists at the Geophysical Fluid Dynamics Laboratory (GFDL), at the Goddard Institute for Space Studies, and at the European Centre for Medium Range Weather Forecasts (ECMWF). This cooperation made it easier for the NMC to follow the lead of Miyakoda at GFDL and Wiin-Nielsen at ECMWF in extending the useful range of its global forecasts to five days.

Brown was born on 28 August, 1930, in Opelousas, Louisiana. His rich southern heritage and a deep love of fishing remained a continuous joy to him throughout his life. He entered the US Air Force in 1951, after receiving the B.Sc. from the University of Southwestern Louisiana. The air force program at Florida State University gave him his first exposure to meteorology. This was followed by several years of forecasting experience for the Strategic Air Command and Air Defense Command at Elmendorf Air Force Base in Alaska. He was then assigned to the Joint Numerical Weather Prediction Unit - the forerunner of NMC - in Suitland, Maryland. His main duties at that time involved the daily analyses and computer runs, leaving little research opportunity. In 1957 he received the M.Sc. in meteorology from the Massachusetts Institute of Technology. He resigned his captain's commission in 1961 to enter the National Weather Service (NWS), but then left one year later to begin a six-year stay at the National Center for Atmospheric Research in Colorado. At this time he worked closely with A. Wiin-Nielsen and did considerable research and publishing on the subject of large-scale energy transformations. He received his doctorate from the University of Colorado before returning to the Development Division at NMC in 1968. His thesis was a numerical exploration of geostrophic instability in a realistic zonal current, and it was written under the guidance of $\mathrm{P}$. Thompson.

Brown contributed to the Society's work in several ways. He was an associate editor of the Journal of Applied Meteorology from 1972 to 1976, and was a member of the Committee on Weather Forecasting and Analysis from 1975 to 1979 . He also served eight important years (1970-1978) on the Committee on Atmospheric Science of the World Meteorological Organization. The AMS recognized his contributions to the profession by electing him as a Fellow in 1973, and by awarding him the Charles L. Mitchell Award in 1987. Within the NWS, he was recognized with many outstanding performance evaluations and, in 1978, with the prestigious Administrator's Award. His many friends in the United States and abroad will treasure the memory of his skillful technical and administrative contributions and will join his wife, Kathleen, in cherishing his personal dedication and friendliness.-Norman A. Phillips

\title{
25 years ago $\ldots$
}

\section{Report on Atmospheric Sciences Released ${ }^{\star}$}

A report calling for a tripling of the national program in the atmospheric sciences over the next decade was submitted in July to the Office of Science and Technology by the National Academy of Sciences-National Research Council.

The three-volume report, The Atmospheric Sciences 1961-1971, describes in considerable detail at least a dozen important areas of the science of the atmosphere requiring attention and support for significant progress. It was developed under the immediate direction and guidance of Dr. Sverre Petterssen, chairman of the Department of the Geophysical Sciences, University of Chicago. The responsible group within the Academy-Research Council was its Committee on Atmospheric Sciences under Dr. Thomas F. Malone, director of research for The Travelers Insurance Companies.

The report states that if the United States is to achieve an adequate

*Bull. Amer. Meteor. Soc., 43, 610. understanding of atmospheric processes, form a sounder scientific basis for weather prediction, and determine the possibilities of modifying man's natural environment on a large scale, then during the next ten years these steps must be taken:

- scientific manpower and the funding of research must be increased threefold;

-the university output of doctorates in the atmospheric sciences must be increased by a factor of at least four or five;

- universities with a crucial role in the graduate and research training programs in this field must broaden and strengthen their programs to become national centers of academic and scientific excellence; and

- government research agencies concerned with the atmospheric sciences must develop more vigorous research and educational programs.

The report is based upon discussions at scientific and technical conferences held during the past year and attended by over 180 scientists. Most of these conferences were held at the AMS headquarters. 